\title{
Integration of Application Software to Create Live-Action Comics into Teaching Materials
}

\author{
Ting-Sheng Weng
}

\begin{abstract}
If teaching materials taught in the classroom can be presented in a dynamic version of live-action comics to explain the contents of the curriculum, then it could attract students' attention, enhance their enthusiasm for learning, and focus their attention on class. This research aims at training and learning the integration of application technologies and to explore and analyze students' learning and growth effects after the process, by inviting three students to participate in the creation of dynamic live-action comic PPT teaching materials. The integration of MomentCam App, Sketch Camera, and PowerPoint along with the addition of special effects has made the dynamic live-action comic materials richer, more lively, and more dynamic, so that it is easier to attract students' learning attention. From the interviews, we learn that students have gained growth during the production process, learned software integration application technology and image processing technology, and found out how to get along with people and the importance of work division and cooperation, which will be an advantage for their entering the workplace in the future. This textbook includes scenarios of teachers and students both being actors in the textbooks, teachers and students entertaining and interacting with each other, students' emotional responses to learning difficulties, their learning to understand, and so on, which are favored by the students and have enhanced the fun teaching results.
\end{abstract}

Index Terms-PPT textbooks, dynamic live-action comic materials, integrated application technology, image processing.

\section{INTRODUCTION}

Literature [1] mentioned that people hope to integrate contemporary technology into teaching in class in order to promote students' learning effectiveness. At present, general curriculum materials are based on the needs of the curriculum while textbooks or images, animations, html, PowerPoint slides, etc. are used to create multimedia teaching materials for radio teaching, online learning, or distance learning. Most of the teaching situations include students listening to the teacher while viewing the textbooks or the content of the media materials provided by the teacher. If students can have dynamic teaching materials to assist their learning in the course, such as presenting course content with dynamic live-action cartoons, then this can attract their attention and allow them to more actively participate in learning.

\section{RESEARCH AND PURPOSES}

\section{A. Research Motives}

For traditional teaching, when teachers are teaching a

Manuscript received September 25, 2018; revised December 8, 2018

T. S. Weng is with the Business Administration Department, National University of Chiayi, West Dist., Chiayi City 60054, Taiwan (R.O.C.) (e-mail: politeweng@mail.ncyu.edu.tw). course they mainly focus on oral presentations and drawing notes in textbooks. They use linear and non-integrated methods to teach, and students are the party that is receiving information. If there are students whose effectiveness at learning in this area is low, then the effectiveness of teaching is limited for these student groups. Literature [2] suggested that appropriate teaching strategies supplemented by information technology are expected to improve teaching quality and student motivation.

This study considers that teachers play the main messaging role in general course textbooks or supplementary textbooks. Although the contents of the lectures are professional and abundant, they may lack the sense of participation of students and make it difficult to attract attention. However, if students are given the primary role of the textbooks, then it will make those students who are uninterested or even afraid of the curriculum feel fresh and interested when they see themselves or their classmates appearing in the textbooks and also becoming the characters, thus reducing their sense of rejection of the curriculum and helping them absorb the knowledge in the process of watching. Taking this motive, the present study explored how to put students into teaching materials to increase the sense of participation and to help them learn different software integration application technologies and Image Processing.

\section{B. Research Purposes}

The purpose of this research is to explore the use of software integration technology to allow teachers and students to become dynamic, live-action comic characters who are integrated into the course materials, thus making the students become interested in the content of the courses. Therefore, students were invited to participate in producing the dynamic PPT live-action comic materials of the supplementary courses, and then the students' experiences in participation were explored, and the effectiveness of learning integrated application technology and Image Processing was discussed.

\section{LITERATURE REVIEW}

\section{A. PPT Teaching Materials}

In modern society the use of computer presentation software, such as Microsoft PowerPoint (PPT), to conduct teaching, lectures, and meeting reports is becoming more and more frequent [3]. Compared to early teaching methods when teachers simply taught orally and used textbooks and paper handouts, the use of newsletters with lecture content as supporting materials is not only lively and interesting, but also enables students to achieve the effect of cognitive understanding [4]. Literature [5] noted that newsletter 
software tools can help with knowledge reorganization and construction. Literature [4] pointed out, on the basis of [6], that media newsletter teaching strategies make a considerable contribution to students' learning effectiveness, as they can integrate teaching contents to make them more standardized and easy to understand. This shortens teaching time, integrates graphics and text, allows students to construct clearer and specific knowledge, and helps improve teaching quality.

Many new methods of information technology have been input into teaching methods in response to the e-era, such as the production of PowerPoint teaching materials, as well as the introduction of multimedia, animation, and comics into teaching. The integration of text, images, and sound makes teaching full of sound, light effects, and charms through diverse, lively, and interesting auxiliary materials [7]. Literature [8] found that using the "newsletter multimedia" teaching strategy to integrate multimedia into a newsletter so as to present abstract concepts helps students improve their interest and willingness to learn, increases opportunities for interaction between teachers and students, and enhances the learning atmosphere of the classroom.

\section{B. Dynamic Live-Action Comic Teaching Materials in $P P T$}

In order to achieve the goal of assisting with appropriate teaching strategies and information technology, animations can be incorporated into course materials. Literature [9] reviewed previous studies by [10]-[15], and suggested that teaching content that has been integrated with animation will make students more interested, increase their learning enthusiasm, and enhance learning effectiveness. Literature [16] mentioned that literature [17] imported photos into EnforManga's system to convert photos into comics, and even multiple photos can be entered at the same time to create a comic book. The dynamic comic teaching materials can increase their attractiveness to students. However, this study believes that integrating teacher-student cartoon characters into teaching materials to make them become a member of the characters in the teaching materials will enable students to have an unprecedented feeling of freshness over the teaching materials.

\section{RESEARCH METHOD}

The students participating in this study are students in the Department of Accounting and Finance, for it is believed that this department has more mathematical scope. The software used included MomentCam App and Sketch Camera. First, the mathematics textbooks for the $12^{\text {th }}$ graders were searched to find the chapters we wanted to make, and examples were then selected. MomentCam was used to make the photos of teachers and group members into a dynamic version of the live-action cartoon (the students were asked to sign a consent form to the comic book characters) via transforming the background, costume, hairstyle, face, etc., and the classroom scene was shot as a comic background. Sketch Camera was used to make the scene look like a hand-painted effect and make the background more distinctive, and a series of realistic sketches of classroom sketches were created. After text and mathematical formulae were entered, PowerPoint was used to integrate with special effects to make the presentations richer and more vivid, which is more likely to attract students' attention to PowerPoint. Fig. 1 shows the flow chart of the comics production.

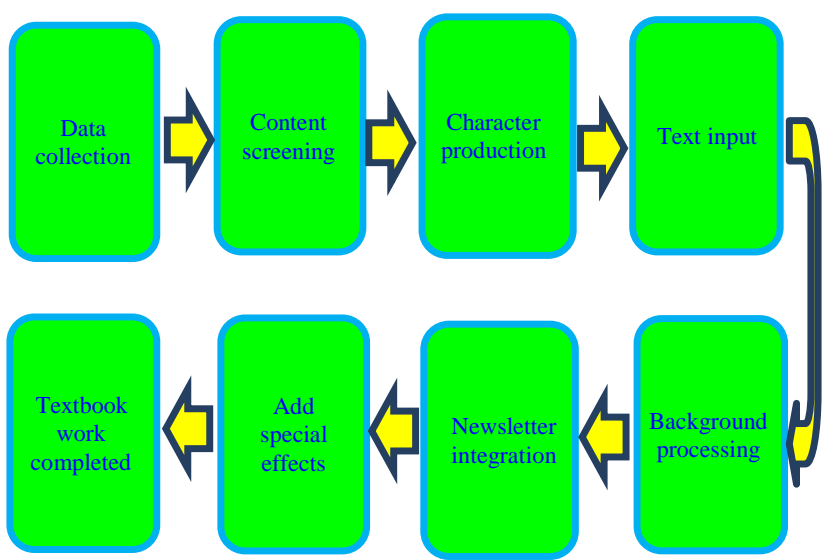

Fig. 1. Flow chart of live-action comic teaching materials of mathematics.

Mathematics has always given people a dull impression. The goal of the students is to change the public's perception of mathematics and make mathematics interesting and lively. Creative ideas presented in the form of live-action cartoons, coupled with easy-to-understand text and examples not only attract the attention of classmates, but also successfully reverse the established impression of mathematics.

Over five weeks, the students who participated in the study were given advice and reminders after each stage of the cartoon creation five times in total in the hope that they could improve their skills and guide the production techniques. Teachers and students were created as comic characters to add more fun to the comics. A dynamic live-action comics PPT textbook with classroom-like interactions between teachers and students in the classroom, emotional difficulties in learning, learning understanding, etc. was made, as shown in Fig. 2.

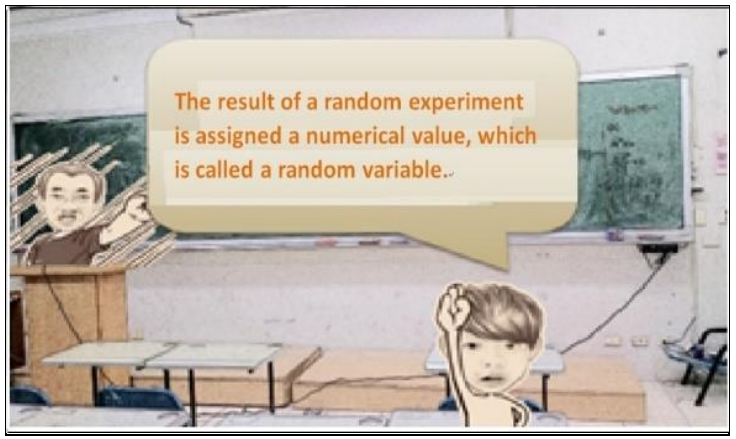

(a) Classroom situation, when the teacher talks to students

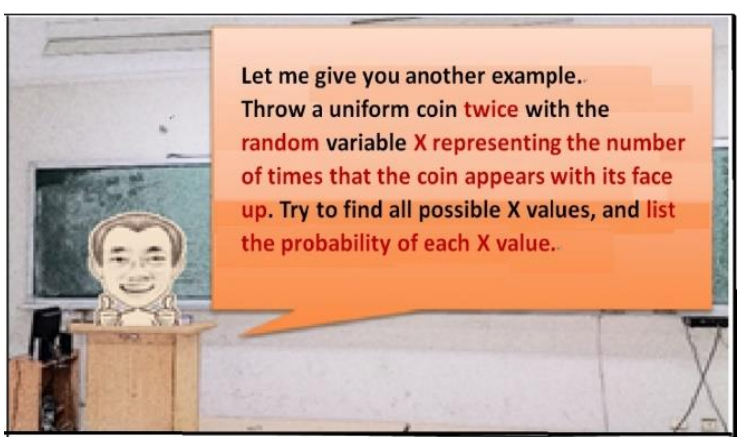

(b) Teacher cites an example of a random variable 


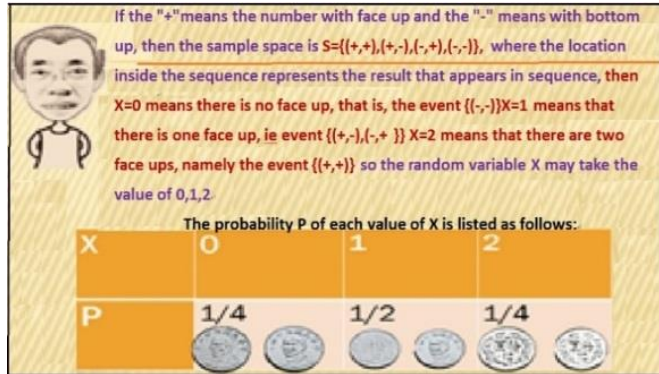

(c) Explanation of examples

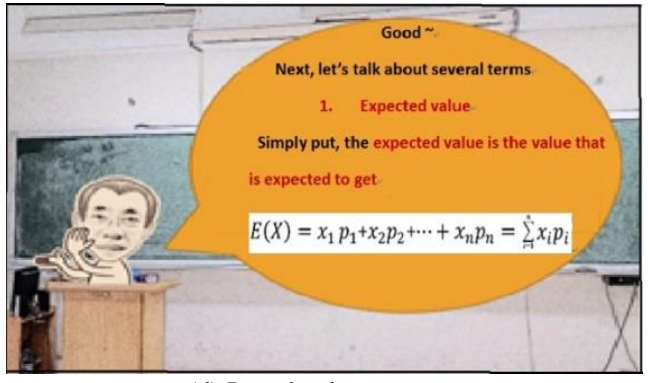

(d) Introduction to terms

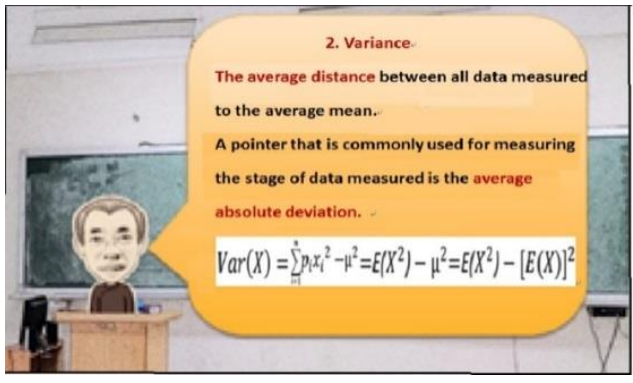

(e) Definition of variance

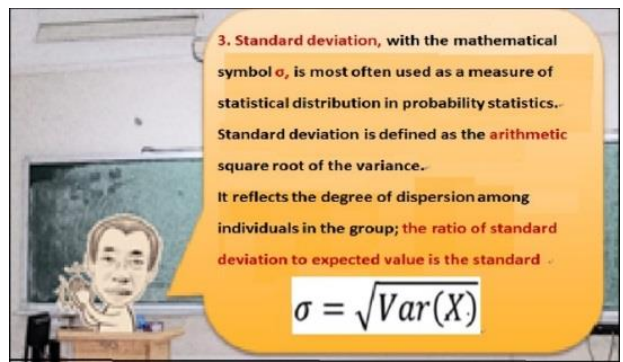

(f) Definition of standard deviation

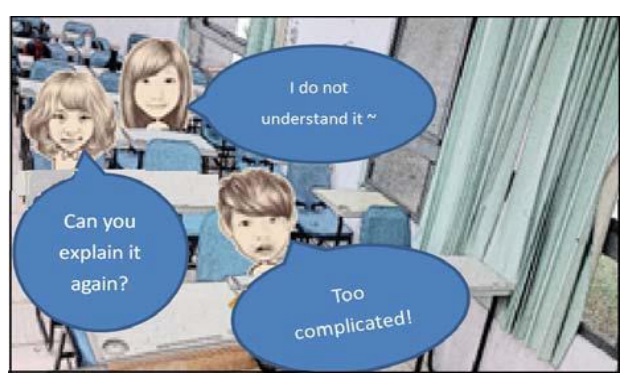

(g) Students find it difficult to understand

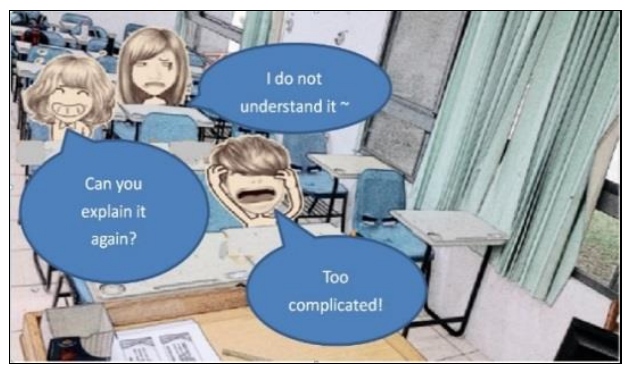

(h) Students' emotional reactions

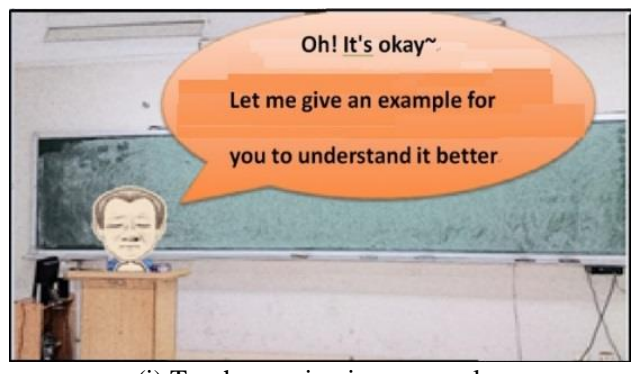

(i) Teacher again gives examples

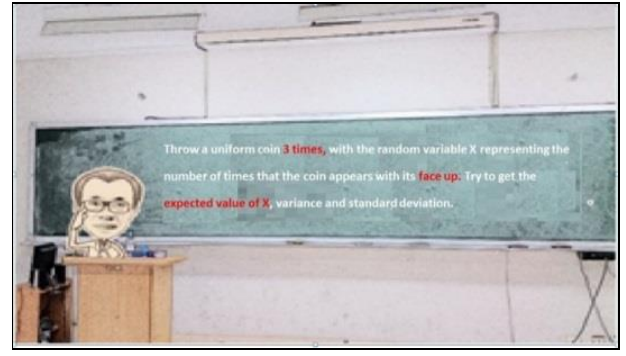

(j) Teacher raises a coin example in the classroom situation

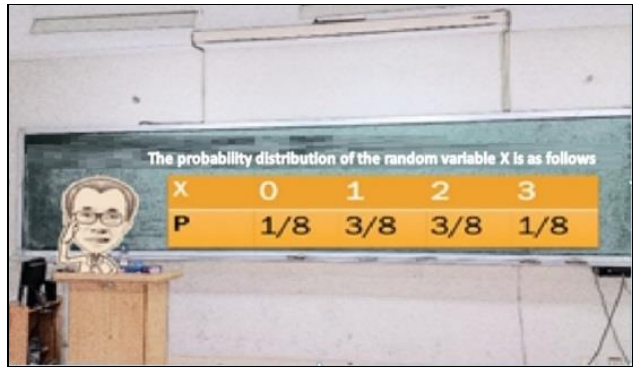

(k) Distribution of random variables

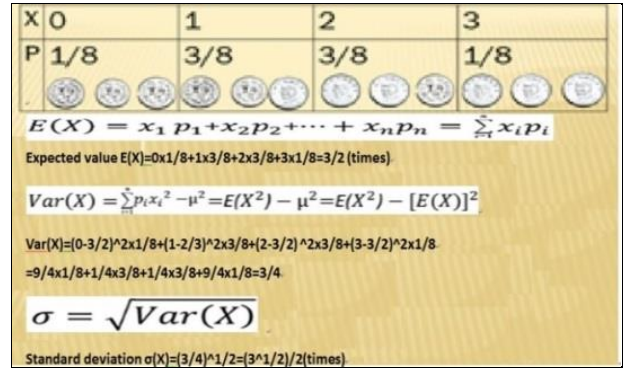

(1) Teacher solves problems

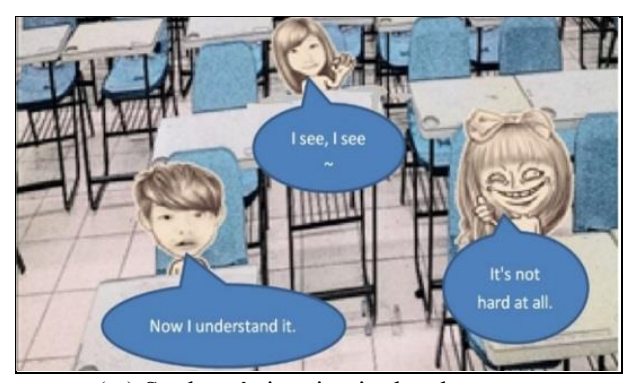

(m) Students' situation in the classroom

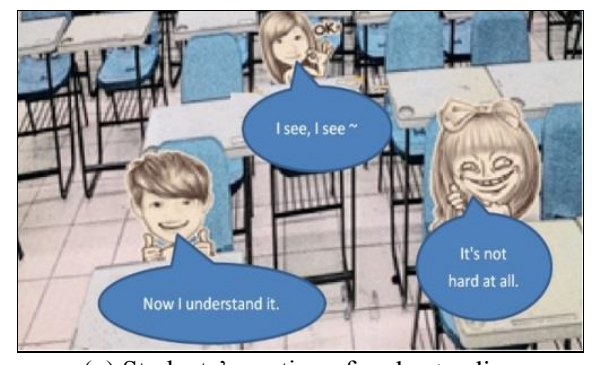

(n) Students' reaction of understanding

Fig. 2. Dynamic PPT classroom situation and dynamic live-action comics teaching material capture image (a to $n$ ). 
During this study, there were 5 times of face-to-face discussions with the students. The students' ideas of drawing are as follows.

Student A: When I was a child, I loved to hold a brush and draw on the paper. I also won a lot of prizes related to painting. When I grew up, because my self-requirements became higher, I felt I couldn't draw the image in my head and became fed up with drawing.

Student B: Drawing is a difficult challenge for me as I have no painting talent.

Student C: I hate drawing. I was most afraid of art classes when I was a child! Because I have no talent for painting, there is no artistic feeling with my works, and the grade is not ideal.

As seen above, the three participating students were not interested in drawing, but they accepted to participate after being talked to.

The students' ideas about the comic book were recorded and organized by this article as follows.

Student A: I used to think that comics are a bit boring and are not interesting enough to attract my attention.

Student B: I like comics, because comics can express content in a dialogue. It can be made cute, interesting, and solemn at the same time.

Student C: I don't like to read comics, but when comics are animated, I like it very much. I think this may be because I don't like to watch static things!

Although all three students were not interested in drawing, one likes comics, one likes animation, and only one is not interested in comics.

The students' ideas of selection of the theme are as follows.

Student A: After the group discussion, according to the range of textbooks proposed by the teacher, we identified relevant books, selected chapters to be produced, collected the key points, and then screened out some exercises as examples in the presentation to help deepen the impression and clarification of concepts.

Student B: The theme was provided by the teacher. The mathematics of the $12^{\text {th }}$ grade is related to the calculus we are learning now, and it is also closely related to things in life. The production can also make me learn and review calculus.

Student C: We chose this topic, because the mathematics of the $12^{\text {th }}$ grade is not far away from us. It is still fresh in my memory, and it is related to the calculus that we are learning so that we can review it through the report. I think it is awesome.

They are from the same dormitory, which is convenient to discuss progress at night. They are not discouraged from mathematics.

The assignment of students is organized as follows.

Student A: The division of labor is based on the strength of the individual. The classmates who are good at focusing on the key points were responsible for the screening of the content. The students who are fast typers were responsible for typing the manuscript. The students who can use the special setting were responsible for making the complex mathematics formulae. The students who make presentations were responsible for integrating all the materials. In addition, the personal photos required for live-action cartoons were for everyone to design their own personal characters. The background photographs were assorted by the students who produced the presentations.

Student B: Before making the report, everyone was assigned his/her own work before starting the assignment. This was more efficient and enabled the assignment to be completed faster.

Student C: The project has been done by the division of labor. Some people were responsible for collecting information. Some were responsible for making the PPT. Some were responsible for the questionnaire design. Everyone contributed as much as possible. No one was lazy.

As seen, they are students who can make good use of time and show good cooperation.

The problems encountered by the student grouping are as follows.

Student A: I am a person who strives for perfection. I hope that the formulae can be presented in a clearer way. However, the original formulae had been completed, and it would take quite a while to change all of them. Therefore, my opinion was not adopted by the group, which made me feel very frustrated.

Student B: In the process of producing the report, it is inevitable that there will be some different opinions and views among team members. Sometimes it caused minor disputes. At that time, we would first express our own opinions and ideas and discuss which one is proper and appropriate.

Student C: In the group I was responsible for picking out the key points or topics in the math textbooks. Some were adopted, some were not, and the reasons for not being adopted were because I didn't get the real focus and the choice was inappropriate.

For example, Student A wanted to express the formula of the score, $(1-2 / 3)^{\wedge} 2 \times 3 / 8$, as $\left[\left(1-\frac{2}{3}\right)^{2} \times \frac{3}{8}\right]$, because Student A personally feels that the latter's representation is better. They then discussed and communicated together to reach a consensus for using the same mathematical formula. Team members have a sense of mission and a consensus for a common purpose.

The students' experiences from their grouping are as follows.

Student A: This production process is a valuable collaborative experience. It taught me to stand in the position of others, to think for others, to respect the opinions of others, and how to communicate with the team members.

Student B: Grouping allows me to learn from interpersonal relationships, to tolerate and respect others, and to better understand what is "unity and strength." In the process, we can learn to help, respect, and cooperate with each other. This is something more meaningful than any result.

Student C: In this assignment I was shaken by the power of solidarity. I am very happy to work side by side with good partners to complete the report, which gives me a great sense of accomplishment. From this I also learned that I must find my positioning and responsibility in the group. As leaders, in addition to leading by example, we must be able to reach out at any time.

They all learned how to respect the opinions of others, communicate and coordinate, find common ground, and form the best solution that can be achieved by the community at that time. What is more valuable is the power of "unity" 
within the collaborations. In the report, everyone gained "valuable experience" and grew more tangibly.

The students' experiences in making animations are as follows.

Student A: The expression in the eyes of our students under the stage watching the report of this group is the greatest affirmation of our accomplishment. Our group has successfully made dull mathematics textbooks into vivid and interesting math textbooks, by using innovative thinking and adding live-action animation and cartoon or other elements. We have created ideas, arranged humorous plots, and added living examples to make the content easier to understand and the key points easier to remember.

Student B: I learned the wonders of mathematics in the production process, which also made me, who was not interested in math, become more and more interested in math. The report was not done for any assignment, but for ourselves. Growing from knowing nothing about software to being handy with it, from having disputes to acceptance, are thing that I have learned the most during the production process. I think that learning in the process is more meaningful and important than the results.

Student C: In this assignment, we added innovative ideas in the form of live-action comics. We also observed and learned the advantages of other groups. We made a final report that all the team members were satisfied with. We got confirmation from our teachers. All of a sudden, all the hard work was worth it.

The PPT animation textbooks, which make student and teacher characters into live-action comics and animation with mathematics application examples in real life, are recognized by students. Students find them interesting and also have more motivation to learn and create more ideas to integrate into the textbooks.

Students also have integrated four management functions, which integrate the experience of producing comics, into the teaching curriculum: planning, organization, leadership, and control. In the planning section, students set goals of hoping to make math fun and attract students' attention and adopted strategies and programs to make cartoons work smoothly and achieve goals. In the organization part, students worked out the types and contents of their work and divided work up according to their strengths. In the leadership part, the team leader assigned work, gave suggestions to the team members, and reminded and motivated the team members in a timely manner to make the team more united. In the control part, the objectives set in the planning were compared with the achievements of the comics to assess whether there was any deviation. The cause of any deviation was identified and corrected to reduce the gap.

The students think that in the future, if live-action comic textbooks can be marketed with commercialization, then they can compare traditional textbooks with creative teaching materials containing live-action cartoons, so that consumers can clearly understand their strengths and weaknesses. Not only does this increase persuasiveness, but it also allows consumers to have a deeper understanding of creative teaching materials. It is also expected to open up the market for creative teaching materials through online marketing to help more students regain their interest in mathematics. The study has learned that students believe the achievements of skill applications can be used as a commodity, and they already have a concept of innovative products. It means that these students are full of innovative thinking capacity and skills.

\section{CONCLUSION}

In order to increase teacher-student interaction, this study suggests using contemporary technology integration skills with the Image Processing function of APP software combined with Power Point for the teacher and the students to enter the textbook as actors and for the content of the textbook to be integrated into the classroom to turn live-action comics into teaching materials. After students actually browse and discuss in the classroom, this dynamic comic textbook can encourage the students to not reject the curriculum and to not fear it, so as to improve their learning effectiveness.

After a class of students in the Department of Accounting and Financial studied the textbook, their ideas for live-action comics and animation-assisted instruction are summarized as follows.

(1) Using a dynamic version of live-action comics to assist teaching can attract students' attention. If the characters are students' favorite idols, then they can also motivate students to learn independently and deepen their impression of the course content.

(2) With different special effects to increase the sense of surprise, students will naturally look forward to the next special effects and are willing to continue reading.

(3) The addition of live-action comics will encourage students who are not interested in the content of the course. For example, it will make boring mathematics more interesting to read.

(4) Many animation effects can attract everyone's attention, reduce the exclusion of mathematics, and cut down on the rate of playing with mobile phones.

(5) Instead of using cartoon characters as in the past, teachers and students themselves are presented as the main character of the comics, which can bring everyone a fresh feeling toward learning.

Based on the above, the dynamic live-action comics incorporated into teaching materials show a positive guiding effect on learning, which can attract students' attention, help their memory, and improve their motivation of learning.

The students benefited greatly from this production process and the review of high school mathematics, which directly contributed to their current study of university calculus. The students also learned more about the function of PowerPoint as well as the method of integrating animation software technology with Image Processing. The students also learned about the division of labor from the grouping and the importance of solidarity, which help students in cooperating with others and giving full play to their strengths after they begin their careers.

The fun style teaching materials with the teacher's and students' real-life photos made into cartoon characters in the textbooks got the attention of the entire class. Moreover, the discussion content of intense interest improved learning effectiveness, indirectly strengthening students' motivation for learning mathematics and improving their learning 
achievement.

\section{SugGeStions}

It is suggested that a follow-up study can be directed toward the production of subjects and course materials that have caused learning pressure and distress to students, so as to improve students' learning motivation.

\section{ACKNOWLEDGMENT}

The author appreciates the comments of the review committee, including Yu-ting Lin, I-chien Chuang, and Tsai-wei Huang.

\section{REFERENCES}

[1] C. S. Yu and Y, H. Liang, "Transformation and regeneration: Reflections on the process of technology integrated into curriculum design," Curriculum \& Instruction Quarterly, vol. 11, no. 3, pp. 129-154, 2008

[2] H. I. Yung and Y. H. Chen, "The effects of applying the zooming function of prezi presentation software in Social studies on elementary students' learning motivations and learning outcomes," Research of Educational Communications and Technology, vol. 105, pp. 59-70, 2013.

[3] C. C. Chiang and H. F. Chou, "The multimodal design of presentation slides: A case study of Steve Jobs's Macworld 2008 keynote," The Journal of Advertising \& Public Relations, vol. 36, pp. 71-97, 2011.

[4] C. L. Chien and L. F. Chang, "Effects on learning between teaching of practical experience and presentation teaching methods-using a course on beverage mixing as an example," Journal of Tainan University of Technology, vol. 30, pp. 125-139, 2011.

[5] K. E. Chang, "View connotation of information integration teaching from the development of learning science and technology," New Taipe City Education, vol. 41, pp. 16-25, 2002.

[6] C. C. Huang, Teaching Media and Student Learning Effectiveness, in Teaching Media Research, Academic Research Council of Normal University ed. Taipei: Wu-Nan Book Inc., 1991, pp. 15-29.

[7] C. P. Chien, G. H. Hwang, L. J. Liang, C. Y. Lee, and Y. S. Wang, "The learning impact of image media integrated into Chinese teaching - An example of art design and non-art design students in a technology university," Journal of Liberal Arts and Social Sciences, vol. 12, no. 4, pp. 277-304, 2016

[8] C. C. Chen and H. H. Chen, "Study on using 'Newsletter Multimedia' teaching strategies in senior electromagnetics," Physics Bimonthly, vol. 28, no. 3, pp. 585-590, 2006

[9] J. M. Kuo, "Instruction with visualization to improve university students' learning effectiveness in general science--- Using computer animation in science curriculum," National Science Council Project pp. 1-20, 2011

[10] L. P. Rieber, "Using computer animated graphics in science instruction with children," Journal of Educational Psychology, vol. 83, pp. 135140, 1990.

[11] W. Schnotz, J. Böckheler, and H. Grzondziel, "Individual and co-operative learning with interactive animated pictures," European Journal of Psychology of Education, vol. 14, pp. 245-265, 1990.

[12] M. Hegarty, S, Kriz, and C. Cate, "The roles of mental animations and external animations in understanding mechanical systems," Cognition and Instruction, vol. 21, pp. 325-360, 2003.

[13] D. Lewalter, "Cognitive strategies for learning form static and dynamic visuals," Learning and Instruction, vol. 13, pp. 177-189, 2003.

[14] H. N. Narayanan and M. Hegarty, "Multimedia design for communication of dynamic information," International Journal of Human Computer Studies, vol.57, pp. 279-315, 2002.

[15] W. Schnotz and T. Rasch, "Enabling, facilitating, and inhibiting effects of animations in multimedia learning: Why reduction of cognitive load can have negative results on learning," Educational Technology Research and Development, vol. 53, pp. 47-58, 2005.

[16] D. L. Way and C. C. Chiang, "Real-time portrait caricature VI deo rendering from facial tracking," National Science Council Project, pp. 1-17, 2012.

[17] H. Tobita and K. Shibasaki, "EnforManga: Interactive comic creation using drag-and-drop and deformation," in Proc. the 11th IEEE International Symposium on Multimedia, pp. 269-274, 2010.

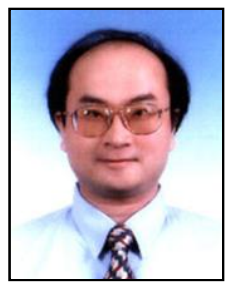

Ting Sheng Weng is an associate professor of the Department of Business Administration at National Chiayi University, Taiwan. He received his $\mathrm{Ph}$. D. in Division of Management and Information Science, Graduate School of Advanced Technology from Kinki University, Japan in 2000. He had served as visiting professor at Meiji University in Japan from 2006 through 2007. His major research interests include science technology and management, e-learning, information education, technology education, animations and comics, MIS, and image processing. 